\title{
Culprit-only versus multivessel percutaneous coronary intervention among STEMI patients complicated by cardiogenic shock in real-world practice: an updated systematic review and meta-analysis
}

\author{
Meng-Jin Hu, Yue-Jin Yang, Wen-Yang Jiang, Jing Xu \\ State Key Laboratory of Cardiovascular Disease, Fuwai Hospital, National Center for Cardiovascular Diseases, Chinese Academy of Medical \\ Sciences \& Peking Union Medical College, Beijing, China \\ Contributions: (I) Conception and design: MJ Hu, YJ Yang; (II) Administrative support: YJ Yang; (III) Provision of study materials or patients: YJ \\ Yang; (IV) Collection and assembly of data: MJ Hu, WY Jiang, J Xu; (V) Data analysis and interpretation: MJ Hu, YJ Yang; (VI) Manuscript writing: \\ All authors; (VII) Final approval of manuscript: All authors. \\ Correspondence to: Yue-Jin Yang, MD, PhD. State Key Laboratory of Cardiovascular Disease, Fuwai Hospital, National Center for Cardiovascular Diseases, \\ Chinese Academy of Medical Sciences \& Peking Union Medical College, 167 Beilishi Road, Beijing 100037, China. Email: yangyjfw@126.com.
}

Background: The recent randomized trials demonstrated that culprit-only percutaneous coronary intervention (CO-PCI) was superior to multivessel PCI (MV-PCI) among ST-segment elevation myocardial infarction (STEMI) patients with multivessel disease (MVD) complicated by cardiogenic shock, yet the realworld scenario remains to be determined.

Methods: Studies that compared CO-PCI versus MV-PCI in STEMI patients with MVD complicated by cardiogenic shock were identified by a systematic search of published articles. Pooled odds ratios (OR) and $95 \%$ confidence intervals (CI) were calculated by using random-effects models.

Results: Eventually, 18 observational studies involving 73,528 patients were included. The results showed that CO-PCI was associated with lower risks of short-term renal failure (OR: $0.75 ; 95 \%$ CI: 0.64 to 0.88 ; $\mathrm{I}^{2}=14.7 \%$ ) and short-term stroke (OR: $0.86 ; 95 \% \mathrm{CI}: 0.77$ to $0.96 ; \mathrm{I}^{2}=0.0 \%$ ) compared with immediate MV-PCI. But the risk of short-term myocardial infarction (OR: 1.12; 95\% CI: 1.03 to $1.22 ; \mathrm{I}^{2}=0.0 \%$ ) was increased. There was no significant difference during long-term follow-up. The results remained consistent after adding the only randomized trial.

Discussion: Based on real-world analyses, our meta-analysis suggested that CO-PCI decreased the risks of renal failure and stroke but increased the risk of myocardial infarction relative to immediate MV-PCI during short-term follow-up in STEMI patients with MVD complicated by cardiogenic shock. If possible in clinical practice, staged MV-PCI can be given a try to decrease the risks of renal failure and stroke associated with immediate MV-PCI and myocardial infarction associated with CO-PCI. However, the conclusions need to be confirmed by further large-scale studies.

Keywords: Multivessel disease (MVD); myocardial infarction; percutaneous coronary intervention (PCI); cardiogenic shock

Submitted May 28, 2021. Accepted for publication Jul 16, 2021.

doi: 10.21037/apm-21-1408

View this article at: https://dx.doi.org/10.21037/apm-21-1408 


\section{Introduction}

It is estimated that approximately $5 \%$ to $10 \%$ of patients with ST-segment elevation myocardial infarction (STEMI) are complicated by cardiogenic shock (1) and the mortality rate of this population is high. The prevalence of multivessel disease (MVD) can approaches as high as $80 \%$ in STEMI patients complicated by cardiogenic shock (2), which is higher than that in patients without cardiogenic shock $(40-65 \%)(3,4)$. MVD is regarded as a risk factor associated with worse outcomes when compared with single-vessel coronary artery disease (3-6). For the treatment of STEMI patients with MVD and cardiogenic shock, the U.S. 2016 appropriate use criteria consider immediate multivessel PCI (MV-PCI), which is defined as revascularization of both infarct related artery (IRA) as well as non-IRA at the same intervention (7). Similarly, the 2017 European Society of Cardiology (ESC) guidelines also recommend non-IRA PCI during the index procedure based on consensus of opinion of the experts (Class IIa, Level C) (8). However, the largest randomized Culprit Lesion Only PCI versus Multivessel PCI in Cardiogenic Shock (CULPRIT-SHOCK) trial (2) suggested that the 30-day composite of death or renal-replacement therapy were lower with culprit-only PCI (CO-PCI) when compared with immediate MV-PCI, thus challenging the guideline recommendations. However, there was no significant difference between the two groups in the composite of death or renal-replacement therapy during one-year follow-up (9). Based on the CULPRIT-SHOCK trial, the European revascularization guidelines have now downgraded immediate MV-PCI in cardiogenic shock patients from a class I to a class III recommendation (10). Moreover, the recent Taiwan Society of Cardiology for the Management of STEMI also suggests that in STEMI patients with MVD complicated by cardiogenic shock, routine non-IRA revascularization during primary PCI is not recommended (11). However, the results based on real-world registry suggested that the 3-year risk of allcause mortality was lower with immediate MV-PCI than that with CO-PCI (12). Considering the fact that in the CULPRIT-SHOCK trial, patients were strictly selected and unable to reflect the real-world situation, we sought to conduct a systematic review and meta-analysis based on real-world analyses to determine if CO-PCI is associated with improved clinical outcomes when compared with immediate MV-PCI in real-world situation. Meanwhile, the CULPRIT-SHOCK trial was just powered for the 30-day analysis of the primary composite of all-cause mortality and renal failure, and significant difference exist in study type, therefore, subgroups according to short- ( $\leq 30$ days) and long-term outcomes ( $\geq 6$ months) and study type were made to investigate the difference between short- and long-term outcomes. The study has been registered in PROSPERO (https://www.crd.york.ac.uk/PROSPERO/), and the register number is CRD42020183124. This study was carried out in compliance with the Preferred Reporting Items for Systematic Reviews and Meta-analyses (PRISMA) 2020 reporting checklist (available at https://dx.doi.org/10.21037/ apm-21-1408) (13).

\section{Methods}

We searched PubMed, EMBASE, the Cochrane database, Web of Science, clinicaltrial.gov, together with Google Scholar for studies from inception to April 2021. The following key words and Medical Subject Headings $(\mathrm{MeSH})$ terms were used to find potential eligible studies: cardiogenic (MeSH), cardiogenic shock, shock, myocardial infarction $(\mathrm{MeSH})$, percutaneous coronary intervention $(\mathrm{MeSH})$, myocardial revascularization $(\mathrm{MeSH})$, multivessel, multivessel, culprit vessel, non-infarct, incomplete revascularization, and complete revascularization. Meanwhile, the presentations at major cardiovascular conferences, the bibliography of original trials, review articles, as well as meta-analyses were also searched to find other eligible studies.

\section{Study selection and data extraction}

In the present meta-analysis, eligible studies were required to fulfill the following criteria: (I) study (sub)group included STEMI patients with MVD and complicated by cardiogenic shock; (II) compared CO-PCI versus MV-PCI strategies; (III) at least 10 patients in each treatment group were included; (IV) published in English language. Studies that concerned about patients undergoing coronary artery bypass grafting were ruled out. Two reviewers (Meng-Jin $\mathrm{Hu}$ and Wen-Yang Jiang) independently assessed the studies for inclusion, and disagreements were resolved by consensus with third-party adjudication (Jing $\mathrm{Xu}$ ). Information with regard to the study period, sample size, study design, definition of MVD and cardiogenic shock, exclusion criteria, clinical outcomes, follow-up time, and baseline characteristics of enrolled patients were extracted. 


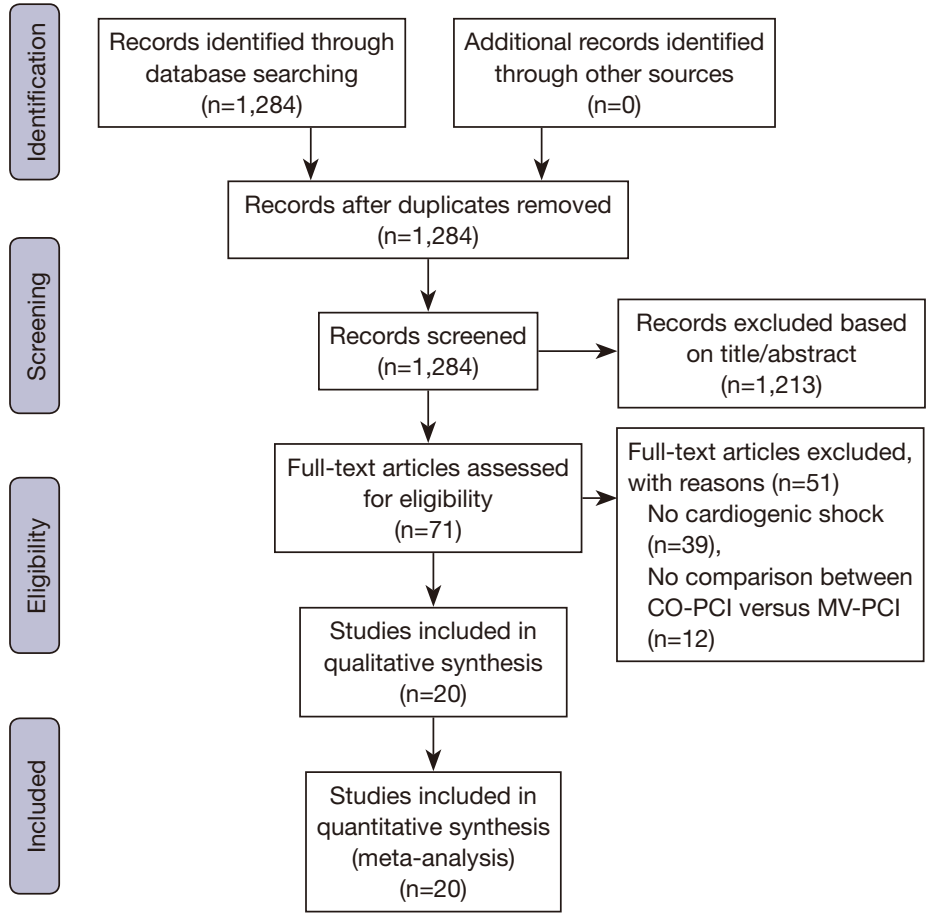

Figure 1 PRISMA flow of the study search and included studies. CABG, coronary artery bypass grafting; CO-PCI, culprit-only percutaneous coronary intervention; MV-PCI, multivessel percutaneous coronary intervention; PRISMA, Preferred Reporting Items for Systematic reviews and Meta-Analyses.

\section{Outcomes}

The primary outcomes for this meta-analysis were all-cause mortality and renal failure on the basis of the definition of separative studies. Secondary outcomes included MACE (major adverse cardiovascular events), cardiac death, myocardial infarction, heart failure, and any revascularization. Safety outcomes including major bleeding and stroke were also investigated. Subgroup analysis according to short( $\leq 30$ days) and long-term ( $\geq 6$ months) follow-up were also investigated.

\section{Statistical analysis}

We extracted raw, unadjusted statistics from each included study. By using Random-effects models of DerSimonian and Laird, we established summary estimate odds ratio (OR) and $95 \%$ confidence interval (CI) for the defined endpoints. Heterogeneity across trials was assessed by using the $\mathrm{I}^{2}$ statistic, with $\mathrm{I}^{2}$ less than $25 \%$ considered low, $25 \%$ to $75 \%$ moderate, and $\mathrm{I}^{2}$ more than $75 \%$ high. By using a leaveone-out analysis, the sensitivity analysis was performed to evaluate whether the summary results were affected by a single study. Meanwhile, the only randomized CULPRITSHOCK trial (2) was added to the results based on observational studies to find out whether the results were influenced by the randomized trial. Publication bias was assessed quantitatively by Egger's linear regression method test or visually by asymmetry in funnel plots. $\mathrm{P}$ value $<0.05$ was considered statistically significant. The meta-analysis was performed by using STATA software, version 14 (StataCorp., College Station, TX, USA).

\section{Results}

\section{Selected studies and characteristics}

Our original search yielded 1,284 articles, after excluding 1,213 irrelevant articles according to titles or abstracts, 71 articles with full text were assessed for eligibility. Among the 71 articles, 51 articles were excluded for the following reasons: no cardiogenic shock, $n=39$, no comparison between CO-PCI versus MV-PCI, n=12. Eventually, a total of 18 observational studies and 2 randomized trials (the same trial) were included in our meta-analysis based on defined inclusion criteria (Figure 1). Of the included studies, 
MV-PCI was all performed in an immediate procedure. As shown in Table 1, among the 73,528 STEMI patients with MVD complicated by cardiogenic shock, 48,611 (66.1\%) patients received CO-PCI, whereas only 24,917 (33.9\%) patients received immediate MV-PCI. Of the included observational studies, 14 were multicenter studies and 4 were single center studies, 10 were prospective and 8 were retrospective studies. MVD was defined using different criteria including stenosis $\geq 50 \%$ in $\geq 2$ major epicardial coronary arteries, $\geq 70 \%$ in $\geq 2$ major epicardial coronary arteries, or left main (LM) stenosis was also defined as two vessel disease. Baseline characteristics of included patients are detailed in Table S1.

\section{Primary outcomes}

Analyses of all-cause mortality revealed that there were no significant differences with CO-PCI compared with immediate MV-PCI during short-term (OR: 0.96; 95\% CI: 0.82 to $1.14 ; \mathrm{I}^{2}=72.2 \%$ ) and long-term (OR: $1.10 ; 95 \%$ CI: 0.88 to $1.36 ; \mathrm{I}^{2}=78.0 \%$ ) follow-up (Figure 2). However, CO-PCI strategy could significantly reduce the risk of short-term renal failure (OR: 0.75; 95\% CI: 0.64 to 0.88 ; $\left.\mathrm{I}^{2}=14.7 \%\right)$ relative to immediate $\mathrm{MV}-\mathrm{PCI}$ strategy, without benefit observed during long-term follow-up (OR: 0.84; 95\% CI: 0.37 to $1.92 ; \mathrm{I}^{2}=29.1 \%$; Figure 3).

\section{Secondary and safety outcomes}

Secondary outcomes including MACE, cardiac death, myocardial infarction, heart failure, and any revascularization as well as safety outcomes including major bleeding and stroke are detailed in Figure 4. In summary, there was a trend indicating that CO-PCI decreased short-term (OR: 0.79; 95\% CI: 0.62 to $1.02 ; \mathrm{I}^{2}=\mathrm{NA}$ ) but increased long-term MACE (OR: 1.08; 95\% CI: 1.00 to $1.18 ; \mathrm{I}^{2}=0.0 \%$ Figure $4 A$ ) relative to immediate MV-PCI. Meanwhile, CO-PCI could increase the risk of myocardial infarction compared with immediate MV-PCI (OR: 1.12; $95 \%$ CI: 1.03 to $1.22 ; \mathrm{I}^{2}=0.0 \%$; Figure $4 C$ ). However, the short-term outcomes indicated that CO-PCI could decrease the risk of stroke (OR: $0.86 ; 95 \%$ CI: 0.77 to $0.96 ; \mathrm{I}^{2}=0.0 \%$; Figure $4 G$ ). There were no significant differences in other outcomes.

\section{Sensitivity and publication bias analyses}

The sensitivity analyses by using a leave-one-out analysis were consistent with the main analyses (Figure S1). The risks of all-cause mortality (Figure S2), renal failure (Figure S3), secondary and safety outcomes (Figure S4) remained concordant after adding the only randomized trial. Moreover, considering the fact that including prospective and retrospective studies in the same analysis may increase the probability of selection bias, a separate analysis of prospective versus retrospective, single center versus multicenter studies was performed. Subgroup analyses of clinical outcomes based on study type can be found in Figure S5. The lower risk of stroke with CO-PCI was mainly confined to retrospective studies (OR: 0.58 ; 95\% CI: 0.34 to $0.99 ; \mathrm{I}^{2}=0.0 \%$; Figure $\mathrm{S} 5 \mathrm{C}$ ). CO-PCI could reduce the risk of renal failure both in multicenter (OR: 0.74; 95\% CI: 0.65 to $0.85 ; \mathrm{I}^{2}=11.0 \%$ ) and prospective studies (OR: 0.75 ; $95 \%$ CI: 0.65 to $0.86 ; \mathrm{I}^{2}=7.8 \%$ ) compared with immediate MV-PCI (Figure S5E). There was no evidence of publication bias with funnel plots (Figure S6) or Begg's test (Figure S7) for any of the above outcomes assessed.

\section{Discussion}

This meta-analysis that compared CO-PCI versus immediate MV-PCI in STEMI patients with MVD and complicated by cardiogenic shock provides a comprehensive aggregate analysis of the available observational studies to date. In analyses based on real-world data, compared with immediate MV-PCI, CO-PCI reduced short-term risks of renal failure and stroke, whereas the short-term risk of myocardial infarction was also increased. The outcomes of short- and long-term all-cause mortality, MACE, cardiac death, heart failure, revascularization, as well as major bleeding were similar between the two groups. The results remained consistent after adding the only randomized trial.

Cardiogenic shock is a serious condition featured by myocardial dysfunction derived from massive myocardium ischemia, increased diastolic stiffness, as well as rapid development of hypoxia, hypotension, tachycardia, and pulmonary congestion (32). In addition, activation of the inflammatory cascade further exacerbates the development vasodilation, hypotension, and hypoperfusion (33). Therefore, considering the low aortic pressure and high left ventricular end-diastolic pressure in patients complicated by cardiogenic shock, it is speculated that immediate MVPCI can improve myocardial perfusion and ventricular function, and hence enable patients to recover from cardiogenic shock. However, it is worthwhile to note that immediate MV-PCI may also lead to harm because of the 


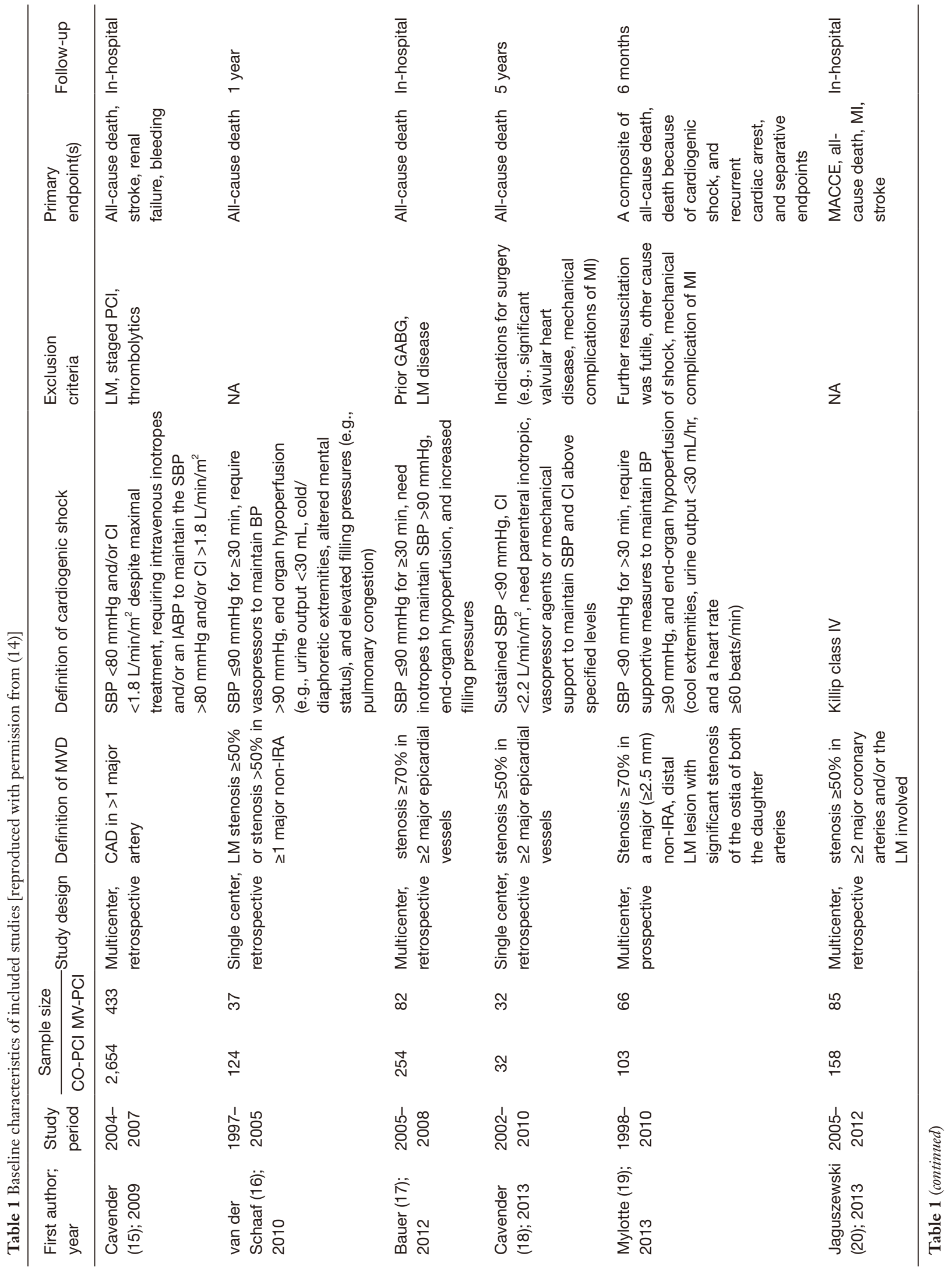




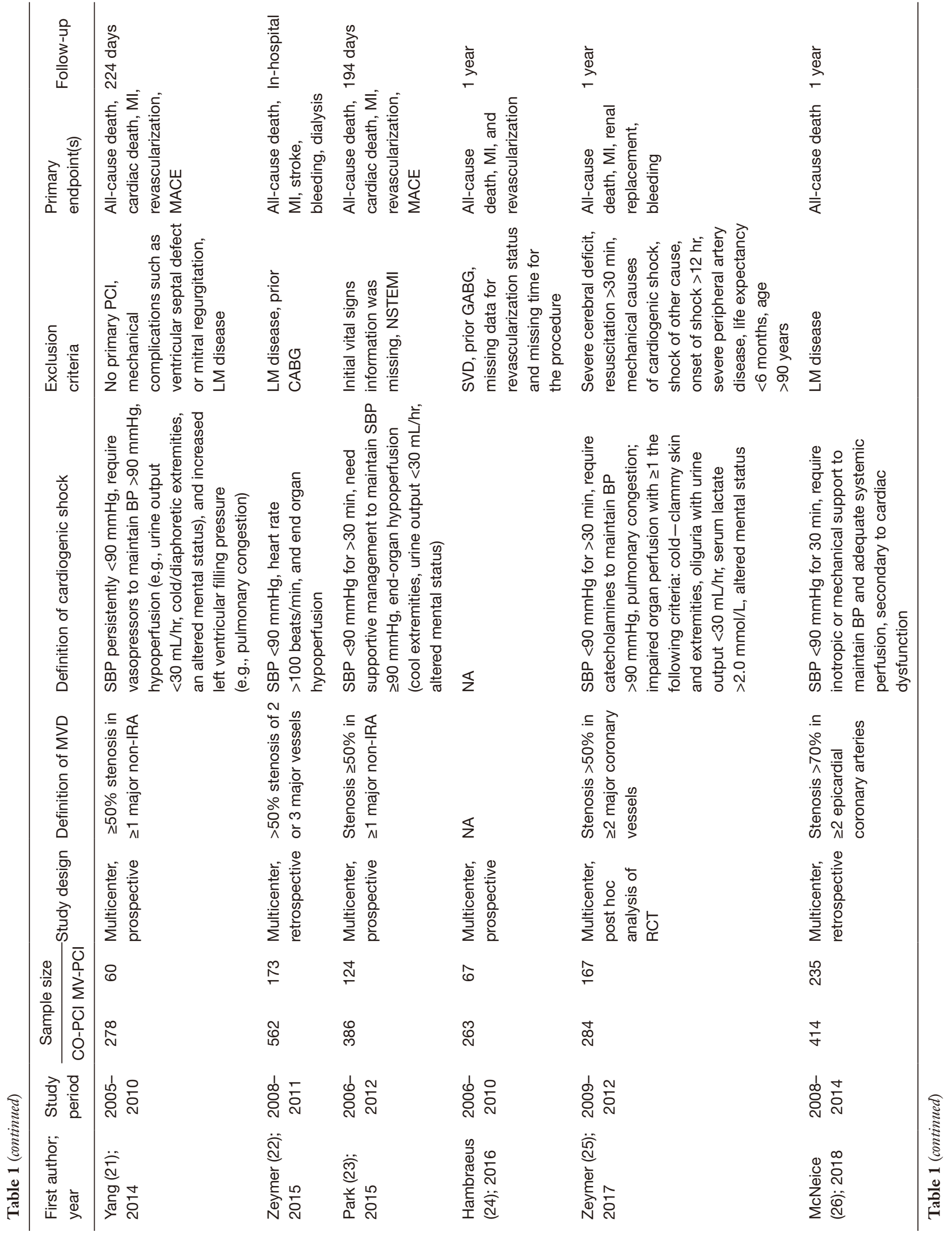




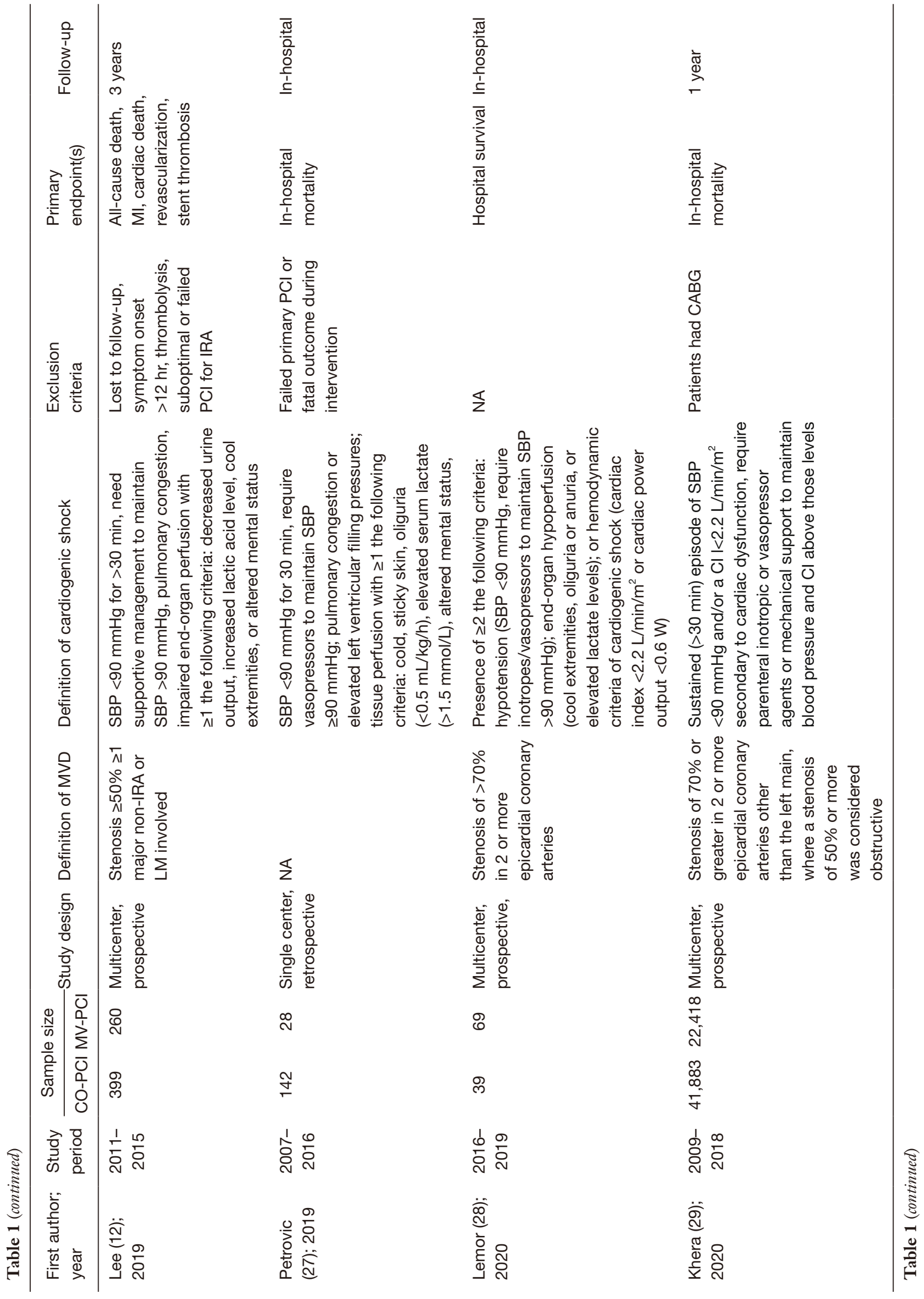




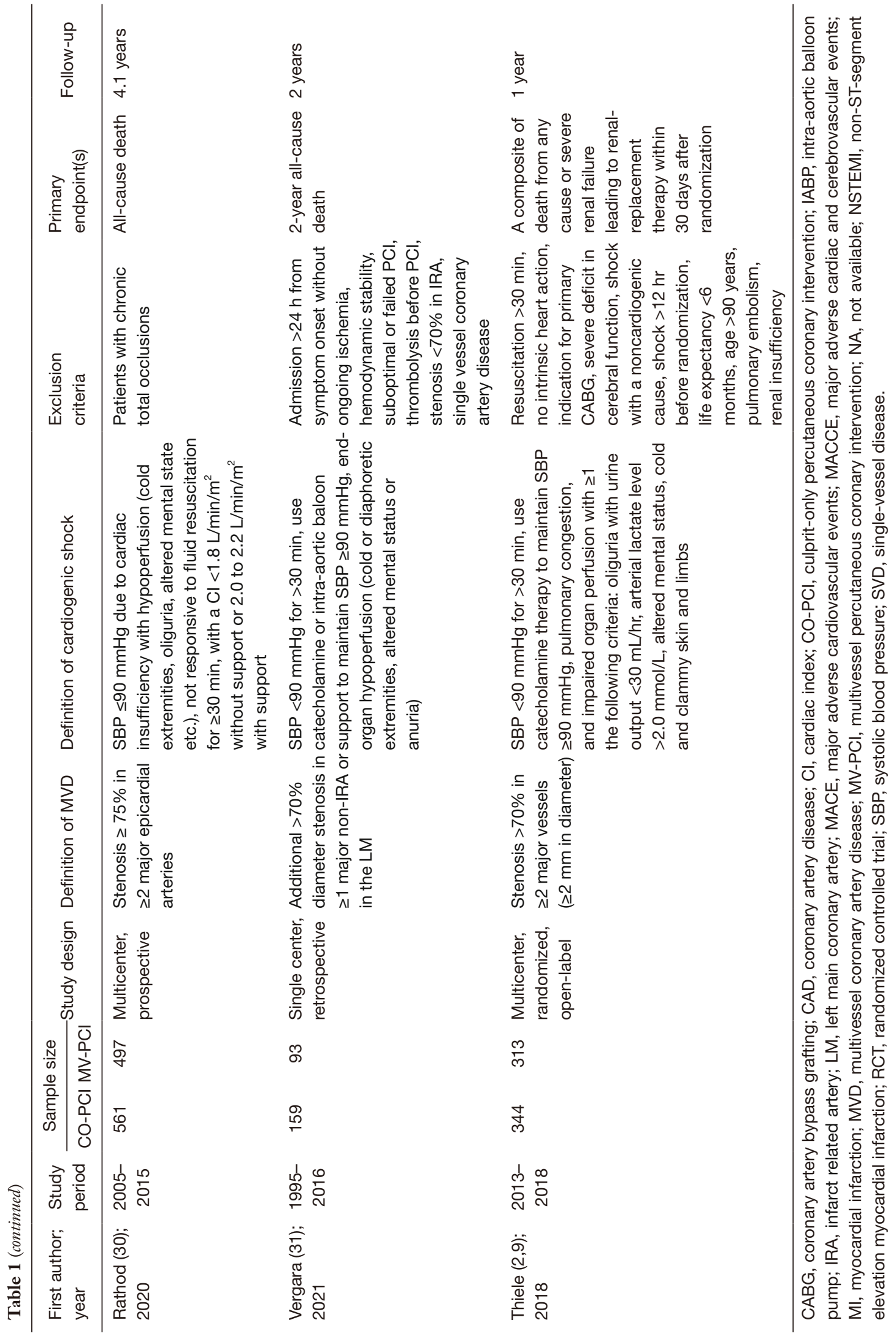




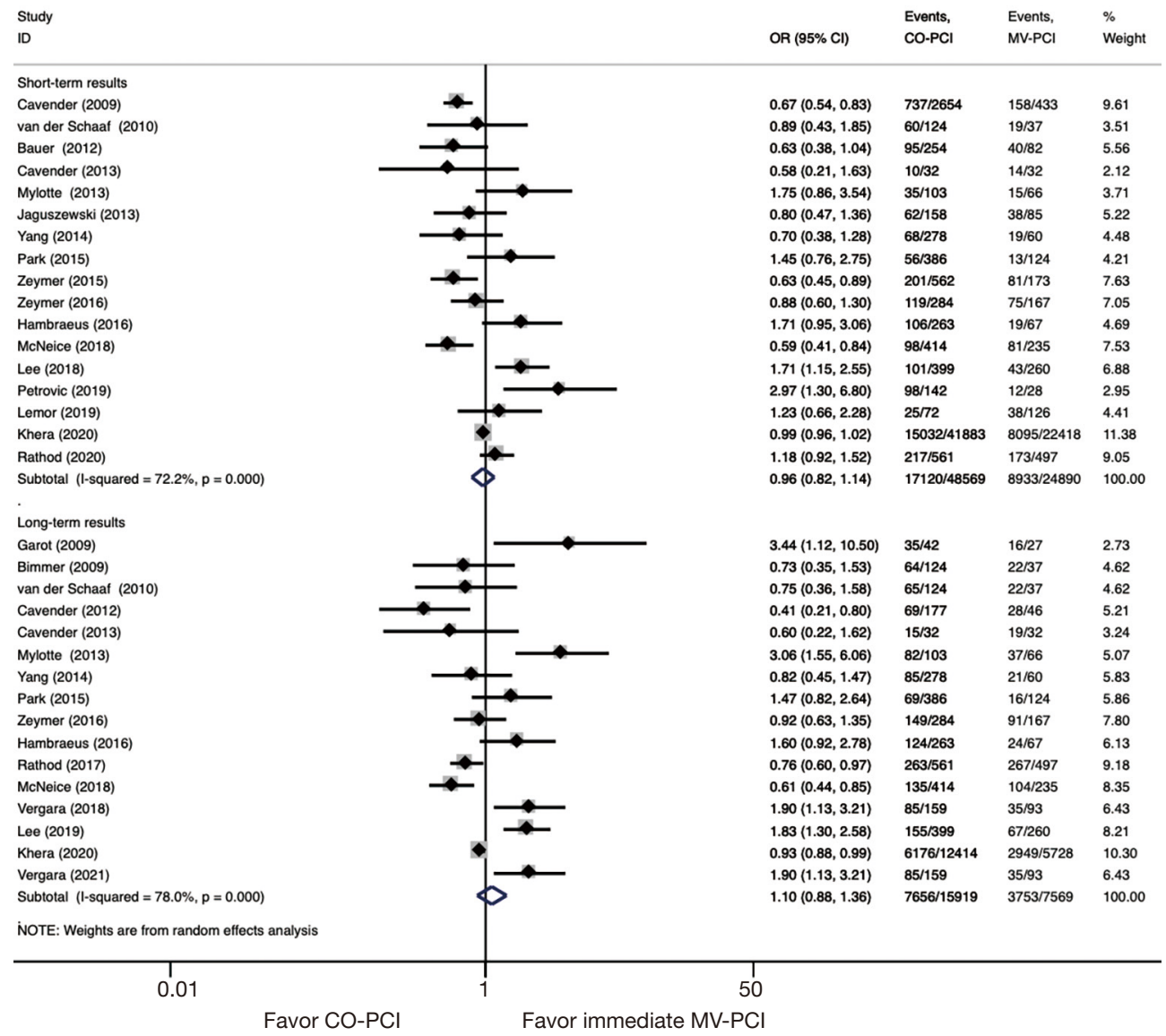

Figure 2 Forest plot of all-cause mortality.

highly prothrombotic and inflammatory milieu, increased procedural time, more contrast use (34), and potential periprocedural complications in the non-IRA. These potential harm may result in higher risks of myocardial infarction and stent thrombosis, even increase the risk of all-cause mortality.

Currently, a large amount of large-scale randomized clinical trials including PRAMI (35), CvLPRIT (36), DANAMI-3-PRIMULTI (37), COMPARE-ACUTE (38), COMPLETE (39) trials, together with meta-analyses $(40,41)$ all suggested that MV-PCI performed in an immediate or staged manner was better than CO-PCI in decreasing the risks of MACE, cardiovascular death, myocardial infarction, and revascularization. However, the problem is that patients with cardiogenic shock were excluded from these randomized trials. Therefore, physicians are supposed to arise awareness about the potential harms associated with MV-PCI when extrapolating these evidence to unstudied populations with cardiogenic shock.

In the largest randomized CULPRIT-SHOCK trial conducted in 83 European centers $(2,9), 706$ patients with cardiogenic shock were randomly assigned to COPCI group ( $\mathrm{n}=351)$ or immediate MV-PCI group ( $\mathrm{n}=355$ ). During 30-days follow up, the primary outcome defined as the composite of death and renal-replacement therapy was lower with the CO-PCI arm when compared with the immediate MV-PCI arm (45.9\% vs. $55.4 \%$; RR: $0.83 ; 95 \% \mathrm{CI}: 0.71$ to $0.96 ; \mathrm{P}=0.01)$. In addition, the incidences of death $(43.3 \%$ vs. $51.6 \%$; RR: $0.84 ; 95 \%$ CI: 0.72 to $0.98 ; \mathrm{P}=0.03$ ) was also lower with $\mathrm{CO}-\mathrm{PCI}$ arm, without significant difference in renal-replacement therapy (11.6\% vs. $16.4 \%$; RR: $0.71 ; 95 \%$ CI: 0.49 to 1.03; $\mathrm{P}=0.07)$. Concordant with the CULPRIT-SHOCK trial, the CathPCI Registry including 64,301 patients also suggested that in-hospital complications (OR: 1.18; 95\% CI: 1.14 to 1.23 ) was also higher in MV-PCI group when compared with CO-PCI group (29). It is postulated that 


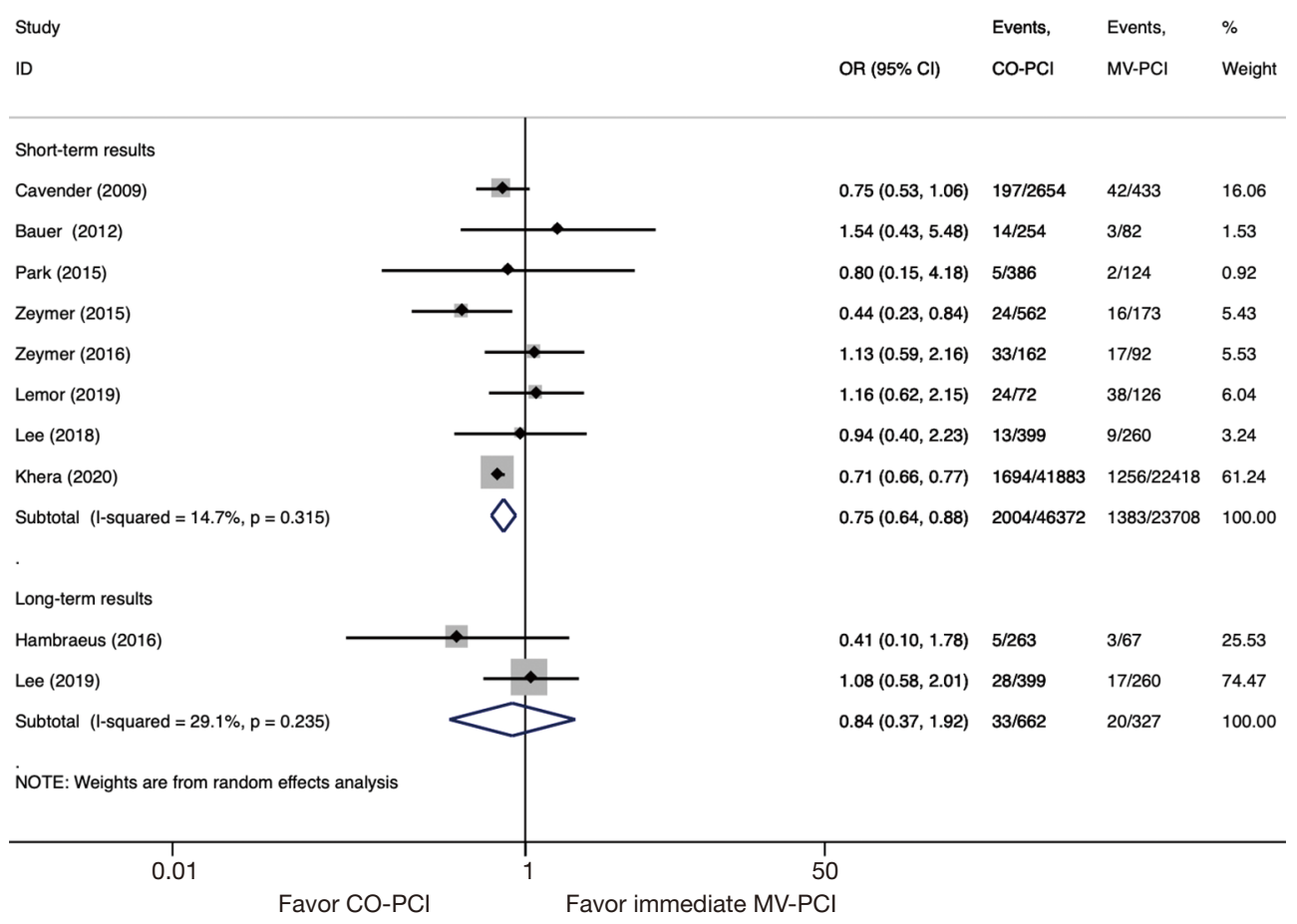

Figure 3 Forest plot of renal failure.

prolonged procedures in MV-PCI group are associated with more blood loss and higher load of iodinated contrast, especially for these patients who already have hemodynamic derangements. Moreover, performing non-IRA PCI may lead to potential procedure-related complications or myocardial injury, these complications or myocardial injury may offset the short-term benefit associated with additional revascularization. At one year, however, the CULPRIT-SHOCK trial indicated that the rate of death (50.0\% vs. $56.9 \%$; RR: 0.88 ; $95 \%$ CI: 0.76 to 1.01 ) and renal-replacement therapy ( $11.6 \%$ vs. $16.4 \%$; RR: 0.71 ; $95 \%$ CI: 0.49 to 1.03$)$ were similar between CO-PCI versus immediate MV-PCI arms, yet rehospitalization due to heart failure (5.2\% vs. $1.2 \%$; RR: 4.46 ; $95 \%$ CI: 1.53 to 13.04$)$ and revascularization $(32.3 \%$ vs. $9.4 \%$; RR: 3.44; $95 \%$ CI, 2.39 to 4.95 ) occurred more frequently with CO-PCI arm. Therefore, in the high-risk STEMI patients with MVD and complicated by cardiogenic shock, it is not suggested to perform immediate MVPCI due to higher incidence of 30-day all-cause mortality. However, just performing CO-PCI may increase the long-term risks of rehospitalization for heart failure and revascularization. In that case, staged $\mathrm{MV}-\mathrm{PCI}$, which perform CO-PCI in the early stage and revascularize
non-IRA at a later time, maybe the optimal option. An international survey including a total of 143 participants suggested that confronted with STEMI patients with MVD complicated by cardiogenic shock, $55.2 \%$ of participants chose to revascularize IRA with staged PCI of non-IRA (staged MV-PCI). CO-PCI (28.0\%), immediate MV-PCI $(11.9 \%)$, and CABG (4.9\%) were standard approaches at some centers (42). In our meta-analysis based on realworld analyses, the short-term myocardial infarction was increased in CO-PCI group, which indicated that after COPCI, staged PCI of non-IRA are supposed to be performed to reduce the risk of myocardial infarction. However, the potential role of staged PCI has not yet been established in a cardiogenic shock population, which should be evaluated in further studies. Moreover, although CO-PCI could reduce the risk of stroke relative to immediate MV-PCI, yet the reduced risk was mainly confined to retrospective studies without significant differences in prospective studies. Therefore, further studies are needed to confirm the influence of immediate MV-PCI on stroke.

\section{Limitations}

First, the 18 included observational studies had limitations 


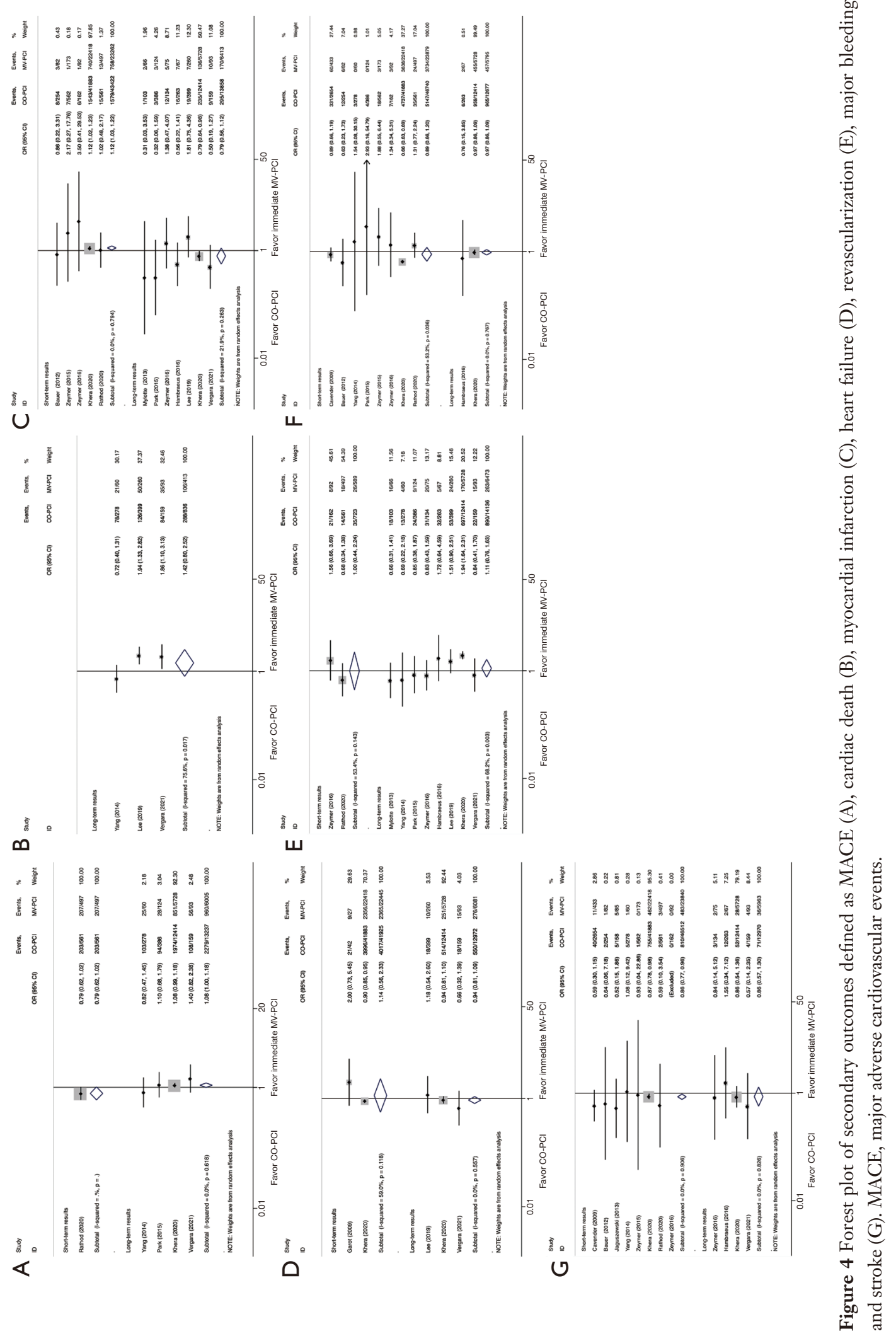


inherent to observational studies such as selection bias and unmeasured confounding. However, these data reflected the real-world scenario in clinical practice. Second, the differences in study period, design, sample size, definition of MVD, exclusion criteria, and follow-up time may increase study heterogeneity and limit the generalization of our conclusions. As shown in the short- $\left(\mathrm{I}^{2}=72.2 \%\right)$ and longterm $\left(\mathrm{I}^{2}=78.0 \%\right)$ all-cause mortality, the heterogeneity was high. We tried to mitigate the heterogeneity by using a random effects model. Meanwhile, subgroup analysis was performed according to follow up time and study type. Third, the study carried out by Khera et al. (29) contained the largest number of patients $(64,301,87.5 \%)$, which may lead to bias for the results of our meta-analysis. However, after excluding the largest study, similar results were still observed. Fourth, data about the severity of shock or hemodynamic parameters were not systematically reported, and records about revascularization success were deficient, which restrained us to complete confounding factors evaluation and draw solid conclusions. Therefore, further studies, especially randomized trials are needed to confirm or refute our conclusions.

\section{Conclusions}

Our meta-analysis shows that in STEMI patients with MVD complicated by cardiogenic shock, CO-PCI could reduce the risks of renal failure and stroke, but increase the risk of myocardial infarction compared with immediate MV-PCI. Similarly, the results in randomized trial also indicated that CO-PCI decreased the short-term composite primary endpoint of death or renal-replacement therapy, yet increased long-term risk of rehospitalization for heart failure and revascularization. Based on these results, COPCI should be considered at the time of primary PCI in STEMI patients with MVD complicated by cardiogenic shock, and if feasible in clinical practice, MV-PCI in a staged procedure can be considered to decrease longterm risks of myocardial infarction, heart failure and revascularization.

\section{Acknowledgments}

We greatly thanked Jiang-Shan Tan and Song Hu for their guidance in software manipulation.

Funding: This work was supported by the CAMS Innovation Fund for Medical Sciences (CIFMS) (2016-I2M-1-009) and the Twelfth Five-Year Planning Project of the Scientific and
Technological Department of China (2011BAI11B02).

\section{Footnote}

Reporting Checklist: The authors have completed the PRISMA 2020 reporting checklist. Available at https:// dx.doi.org/10.21037/apm-21-1408

Conflicts of Interest: All authors have completed the ICMJE uniform disclosure form (available at https://dx.doi. org/10.21037/apm-21-1408). The authors report that this work was supported by the CAMS Innovation Fund for Medical Sciences (CIFMS) (2016-I2M-1-009) and the Twelfth Five-Year Planning Project of the Scientific and Technological Department of China (2011BAI11B02).

Ethical Statement: The authors are accountable for all aspects of the work in ensuring that questions related to the accuracy or integrity of any part of the work are appropriately investigated and resolved.

Open Access Statement: This is an Open Access article distributed in accordance with the Creative Commons Attribution-NonCommercial-NoDerivs 4.0 International License (CC BY-NC-ND 4.0), which permits the noncommercial replication and distribution of the article with the strict proviso that no changes or edits are made and the original work is properly cited (including links to both the formal publication through the relevant DOI and the license). See: https://creativecommons.org/licenses/by-nc-nd/4.0/.

\section{References}

1. Reyentovich A, Barghash MH, Hochman JS. Management of refractory cardiogenic shock. Nat Rev Cardiol 2016;13:481-92.

2. Thiele H, Akin I, Sandri M, et al. PCI Strategies in Patients with Acute Myocardial Infarction and Cardiogenic Shock. N Engl J Med 2017;377:2419-32.

3. Jaski BE, Cohen JD, Trausch J, et al. Outcome of urgent percutaneous transluminal coronary angioplasty in acute myocardial infarction: comparison of single-vessel versus multivessel coronary artery disease. Am Heart J 1992;124:1427-33.

4. Moreno R, García E, Elízaga J, et al. Results of primary angioplasty in patients with multivessel disease. Rev Esp Cardiol 1998;51:547-55.

5. Kahn JK, Rutherford BD, McConahay DR, et al. Results 
of primary angioplasty for acute myocardial infarction in patients with multivessel coronary artery disease. J Am Coll Cardiol 1990;16:1089-96.

6. Muller DW, Topol EJ, Ellis SG, et al. Multivessel coronary artery disease: a key predictor of short-term prognosis after reperfusion therapy for acute myocardial infarction. Thrombolysis and Angioplasty in Myocardial Infarction (TAMI) Study Group. Am Heart J 1991;121:1042-9.

7. Patel MR, Calhoon JH, Dehmer GJ, et al. ACC/AATS/ AHA/ASE/ASNC/SCAI/SCCT/STS 2016 Appropriate Use Criteria for Coronary Revascularization in Patients With Acute Coronary Syndromes: A Report of the American College of Cardiology Appropriate Use Criteria Task Force, American Association for Thoracic Surgery, American Heart Association, American Society of Echocardiography, American Society of Nuclear Cardiology, Society for Cardiovascular Angiography and Interventions, Society of Cardiovascular Computed Tomography, and the Society of Thoracic Surgeons. J Am Coll Cardiol 2017;69:570-91.

8. Ibanez B, James S, Agewall S, et al. 2017 ESC Guidelines for the management of acute myocardial infarction in patients presenting with ST-segment elevation: The Task Force for the management of acute myocardial infarction in patients presenting with ST-segment elevation of the European Society of Cardiology (ESC). Eur Heart J 2018;39:119-77.

9. Thiele H, Akin I, Sandri M, et al. One-Year Outcomes after PCI Strategies in Cardiogenic Shock. N Engl J Med 2018;379:1699-710.

10. Neumann FJ, Sousa-Uva M, Ahlsson A, et al. 2018 ESC/ EACTS Guidelines on myocardial revascularization. The Task Force on myocardial revascularization of the European Society of Cardiology (ESC) and European Association for Cardio-Thoracic Surgery (EACTS). G Ital Cardiol (Rome) 2019;20:1s-61s.

11. Li YH, Lee CH, Huang WC, et al. 2020 Focused Update of the 2012 Guidelines of the Taiwan Society of Cardiology for the Management of ST-Segment Elevation Myocardial Infarction. Acta Cardiol Sin 2020;36:285-307.

12. Lee JM, Rhee TM, Kim HK, et al. Comparison of LongTerm Clinical Outcome Between Multivessel Percutaneous Coronary Intervention Versus Infarct-Related ArteryOnly Revascularization for Patients With ST-SegmentElevation Myocardial Infarction With Cardiogenic Shock. J Am Heart Assoc 2019;8:e013870.

13. PRISMA 2020. J Clin Epidemiol 2021;134:A5-6.

14. Hu MJ, Li XS, Jin C, et al. Does multivessel revascularization fit all patients with STEMI and multivessel coronary artery disease? A systematic review and meta-analysis. Int J Cardiol Heart Vasc 2021;35:100813.

15. Cavender MA, Milford-Beland S, Roe MT, et al. Prevalence, predictors, and in-hospital outcomes of noninfarct artery intervention during primary percutaneous coronary intervention for ST-segment elevation myocardial infarction (from the National Cardiovascular Data Registry). Am J Cardiol 2009;104:507-13.

16. van der Schaaf RJ, Claessen BE, Vis MM, et al. Effect of multivessel coronary disease with or without concurrent chronic total occlusion on one-year mortality in patients treated with primary percutaneous coronary intervention for cardiogenic shock. Am J Cardiol 2010;105:955-9.

17. Bauer T, Zeymer U, Hochadel M, et al. Use and outcomes of multivessel percutaneous coronary intervention in patients with acute myocardial infarction complicated by cardiogenic shock (from the EHS-PCI Registry). Am J Cardiol 2012;109:941-6.

18. Cavender MA, Rajeswaran J, DiPaola L, et al. Outcomes of culprit versus multivessel PCI in patients with multivessel coronary artery disease presenting with STelevation myocardial infarction complicated by shock. J Invasive Cardiol 2013;25:218-24.

19. Mylotte D, Morice MC, Eltchaninoff H, et al. Primary percutaneous coronary intervention in patients with acute myocardial infarction, resuscitated cardiac arrest, and cardiogenic shock: the role of primary multivessel revascularization. JACC Cardiovasc Interv 2013;6:115-25.

20. Jaguszewski M, Radovanovic D, Nallamothu BK, et al. Multivessel versus culprit vessel percutaneous coronary intervention in ST-elevation myocardial infarction: is more worse? EuroIntervention 2013;9:909-15.

21. Yang JH, Hahn JY, Song PS, et al. Percutaneous coronary intervention for nonculprit vessels in cardiogenic shock complicating ST-segment elevation acute myocardial infarction. Crit Care Med 2014;42:17-25.

22. Zeymer U, Hochadel M, Thiele H, et al. Immediate multivessel percutaneous coronary intervention versus culprit lesion intervention in patients with acute myocardial infarction complicated by cardiogenic shock: results of the ALKK-PCI registry. EuroIntervention 2015;11:280-5.

23. Park JS, Cha KS, Lee DS, et al. Culprit or multivessel revascularisation in ST-elevation myocardial infarction with cardiogenic shock. Heart 2015;101:1225-32.

24. Hambraeus K, Jensevik K, Lagerqvist B, et al. Long- 
Term Outcome of Incomplete Revascularization After Percutaneous Coronary Intervention in SCAAR (Swedish Coronary Angiography and Angioplasty Registry). JACC Cardiovasc Interv 2016;9:207-15.

25. Zeymer U, Werdan K, Schuler G, et al. Editor's ChoiceImpact of immediate multivessel percutaneous coronary intervention versus culprit lesion intervention on 1-year outcome in patients with acute myocardial infarction complicated by cardiogenic shock: Results of the randomised IABP-SHOCK II trial. Eur Heart J Acute Cardiovasc Care 2017;6:601-9.

26. McNeice A, Nadra IJ, Robinson SD, et al. The prognostic impact of revascularization strategy in acute myocardial infarction and cardiogenic shock: Insights from the British Columbia Cardiac Registry. Catheter Cardiovasc Interv 2018;92:E356-E367.

27. Petrovic M, Jarakovic M, Cankovic M, et al. Complete percutaneous myocardial revascularization in patients with STEMI complicated by cardiogenic shock. Vojnosanitetski Pregled 2019;76:152-60.

28. Lemor A, Basir MB, Patel K, et al. Multivessel Versus Culprit-Vessel Percutaneous Coronary Intervention in Cardiogenic Shock. JACC Cardiovasc Interv 2020;13:1171-8.

29. Khera R, Secemsky EA, Wang Y, et al. Revascularization Practices and Outcomes in Patients With Multivessel Coronary Artery Disease Who Presented With Acute Myocardial Infarction and Cardiogenic Shock in the US, 2009-2018. JAMA Intern Med 2020;180:1317-27.

30. Rathod KS, Koganti S, Jain AK, et al. Complete Versus Culprit only Revascularisation in Patients with Cardiogenic Shock Complicating Acute Myocardial Infarction: Incidence and Outcomes from the London Heart Attack Group. Cardiovasc Revasc Med 2020;21:350-8.

31. Vergara R, Vignini E, Ciabatti M, et al. Long-Term Mortality Comparison of Patients With Acute Myocardial Infarction Complicated by Cardiogenic Shock and Treated With Culprit-Only or Multivessel Percutaneous Coronary Intervention. Cardiovasc Revasc Med 2021;22:10-5.

32. Hollenberg SM, Kavinsky CJ, Parrillo JE. Cardiogenic shock. Ann Intern Med 1999;131:47-59.

33. Kohsaka S, Menon V, Lowe AM, et al. Systemic inflammatory response syndrome after acute myocardial infarction complicated by cardiogenic shock. Arch Intern Med 2005;165:1643-50.

34. Klingenberg R, Brokopp CE, Grivès A, et al. Clonal restriction and predominance of regulatory $\mathrm{T}$ cells in coronary thrombi of patients with acute coronary syndromes. Eur Heart J 2015;36:1041-8.

35. Wald DS, Morris JK, Wald NJ, et al. Randomized trial of preventive angioplasty in myocardial infarction. N Engl J Med 2013;369:1115-23.

36. Gershlick AH, Khan JN, Kelly DJ, et al. Randomized trial of complete versus lesion-only revascularization in patients undergoing primary percutaneous coronary intervention for STEMI and multivessel disease: the CvLPRIT trial. J Am Coll Cardiol 2015;65:963-72.

37. Engstrøm T, Kelbæk H, Helqvist S, et al. Complete revascularisation versus treatment of the culprit lesion only in patients with ST-segment elevation myocardial infarction and multivessel disease (DANAMI-3PRIMULTI): an open-label, randomised controlled trial. Lancet 2015;386:665-71.

38. Smits PC, Abdel-Wahab M, Neumann FJ, et al. Fractional Flow Reserve-Guided Multivessel Angioplasty in Myocardial Infarction. N Engl J Med 2017;376:1234-44.

39. Mehta SR, Wood DA, Storey RF, et al. Complete Revascularization with Multivessel PCI for Myocardial Infarction. N Engl J Med 2019;381:1411-21.

40. Anantha Narayanan M, Reddy YN, Sundaram V, et al. What is the optimal approach to a non- culprit stenosis after ST-elevation myocardial infarction - Conservative therapy or upfront revascularization? An updated meta-analysis of randomized trials. Int J Cardiol 2016;216:18-24.

41. Elgendy IY, Mahmoud AN, Kumbhani DJ, et al. Complete or Culprit-Only Revascularization for Patients With Multivessel Coronary Artery Disease Undergoing Percutaneous Coronary Intervention: A Pairwise and Network Meta-Analysis of Randomized Trials. JACC Cardiovasc Interv 2017;10:315-24.

42. Smilowitz NR, Galloway AC, Ohman EM, et al. Coronary revascularization and circulatory support strategies in patients with myocardial infarction, multi-vessel coronary artery disease, and cardiogenic shock: Insights from an international survey. Am Heart J 2020;225:55-9.

Cite this article as: $\mathrm{Hu}$ MJ, Yang YJ, Jiang WY, Xu J. Culpritonly versus multivessel percutaneous coronary intervention among STEMI patients complicated by cardiogenic shock in real-world practice: an updated systematic review and metaanalysis. Ann Palliat Med 2021;10(8):8628-8641. doi: 10.21037/ apm-21-1408 
Table S1 Baseline characteristics of included patients

\begin{tabular}{|c|c|c|c|c|c|c|c|c|c|c|c|}
\hline $\begin{array}{l}\text { First Author; } \\
\text { Year }\end{array}$ & Group & Age (years) & Male (\%) & $\begin{array}{c}\text { Hypertension } \\
(\%)\end{array}$ & $\begin{array}{l}\text { Hyperlipidemia } \\
\text { (\%) }\end{array}$ & Diabetes (\%) & $\begin{array}{c}\text { Smoking } \\
(\%)\end{array}$ & $\begin{array}{l}\text { Heart rate } \\
\text { (beats/min) }\end{array}$ & $\mathrm{SBP}(\mathrm{mm} \mathrm{Hg})$ & LVEF & $\begin{array}{l}\text { Three vessel } \\
\text { disease (\%) }\end{array}$ \\
\hline $\begin{array}{l}\text { Cavender (15), } \\
2009\end{array}$ & $\begin{array}{l}\text { CO-PCl; } \\
\text { MV-PCl }\end{array}$ & $\begin{array}{l}66.312 .8 \\
66.413 .0\end{array}$ & $64.7 ; 64.2$ & 63.4; 59.8 & $50.7 ; 50.6$ & $27.3 ; 30.5$ & $62.1 ; 56.1$ & NA & NA & NA & NA \\
\hline $\begin{array}{l}\text { van der Schaaf } \\
(16), 2010\end{array}$ & $\begin{array}{l}\text { CO-PCl; } \\
\text { MV-PCl }\end{array}$ & $\begin{array}{c}67.411 .4 \\
6713.3\end{array}$ & $67.7 ; 81.1$ & $25.8 ; 29.7$ & $24.2 ; 24.3$ & $21.8 ; 24.3$ & $29.8 ; 29.7$ & NA & NA & NA & $53.2 ; 62.2$ \\
\hline $\begin{array}{l}\text { Bauer (17), } \\
2012\end{array}$ & $\begin{array}{l}\mathrm{CO}-\mathrm{PCl} ; \\
\mathrm{MV}-\mathrm{PCl}\end{array}$ & $\begin{array}{l}65.412 .2 \\
67.212 .2\end{array}$ & $68 ; 71$ & $67 ; 60$ & $55 ; 47$ & $35 ; 40$ & $54 ; 55$ & NA & NA & NA & $46 ; 51$ \\
\hline $\begin{array}{l}\text { Cavender (18), } \\
2013\end{array}$ & $\begin{array}{l}\mathrm{CO}-\mathrm{PCl} ; \\
\mathrm{MV}-\mathrm{PCl}\end{array}$ & $6613 ; 6314$ & $62 ; 72$ & $79 ; 72$ & $24 ; 16$ & $31 ; 35$ & $71 ; 67$ & $8521 ; 9427$ & $\begin{array}{l}10726 \\
10623\end{array}$ & $3214 ; 249$ & $52 ; 51$ \\
\hline $\begin{array}{l}\text { Mylotte (19), } \\
2013\end{array}$ & $\begin{array}{l}\text { CO-PCl; } \\
\text { MV-PCl }\end{array}$ & $\begin{array}{c}68.511 .8 \\
6512.4\end{array}$ & $71.9 ; 75.8$ & $48.5 ; 53$ & $40.8 ; 45.5$ & $25.2 ; 25.8$ & $31.1 ; 34.8$ & $9821.2 ; 9520$ & $\begin{array}{l}8321.2 \\
8215.7\end{array}$ & $\begin{array}{l}30.39 \\
319.6\end{array}$ & $47.6 ; 51.5$ \\
\hline $\begin{array}{l}\text { Jaguszewski } \\
(20), 2013\end{array}$ & $\begin{array}{l}\mathrm{CO}-\mathrm{PCl} ; \\
\mathrm{MV}-\mathrm{PCl}\end{array}$ & $\begin{array}{c}6511.2 \\
64.711 .7\end{array}$ & $74.7 ; 77.6$ & $61.1 ; 56.5$ & $57.9 ; 39.7$ & $25 ; 26.1$ & $54.5 ; 57.1$ & NA & NA & NA & NA \\
\hline Yang (21), 2014 & $\begin{array}{l}\mathrm{CO}-\mathrm{PCl} ; \\
\mathrm{MV}-\mathrm{PCl}\end{array}$ & $70 ; 57$ & $57.9 ; 63.3$ & $57.9 ; 50$ & $23.4 ; 21.7$ & $16.5 ; 21.7$ & $35.6 ; 40$ & $\begin{array}{l}66.532 .7 \\
71.835 .2\end{array}$ & $\begin{array}{c}8339 ; \\
87.633 .8\end{array}$ & $\begin{array}{l}45.913 .9 \\
48.515 .3\end{array}$ & $44.2 ; 46.7$ \\
\hline $\begin{array}{l}\text { Zeymer (22), } \\
2015\end{array}$ & $\begin{array}{l}\text { CO-PCl; } \\
\text { MV-PCl }\end{array}$ & $70 ; 68$ & $71 ; 72$ & $78 ; 81$ & $69 ; 69$ & $35 ; 39$ & $39 ; 32$ & NA & NA & NA & $62 ; 70$ \\
\hline Park (23), 2015 & $\begin{array}{l}\text { CO-PCl; } \\
\text { MV-PCl }\end{array}$ & $68 ; 65.5$ & $65.8 ; 71$ & $54.5 ; 53.7$ & $9.7 ; 9.8$ & $23.3 ; 25.6$ & $46.6 ; 47.6$ & $62 ; 66$ & $80 ; 80$ & $\begin{array}{l}50.311 .1 \\
49.815 .3\end{array}$ & $39.9 ; 46$ \\
\hline $\begin{array}{l}\text { Hambraeus (24), } \\
2016\end{array}$ & $\begin{array}{l}\text {, CO-PCl; } \\
\text { MV-PCl }\end{array}$ & $\begin{array}{l}\text { 71.310.9; } \\
68.211 .8\end{array}$ & $65.4 ; 67.2$ & $39.5 ; 38.8$ & $16.7 ; 22.4$ & $23.6 ; 26.9$ & $41.9 ; 49.3$ & NA & NA & NA & $51.3 ; 25.4$ \\
\hline $\begin{array}{l}\text { Zeymer (25), } \\
2017\end{array}$ & $\begin{array}{l}\mathrm{CO}-\mathrm{PCl} ; \\
\mathrm{MV}-\mathrm{PCl}\end{array}$ & $6812 ; 6912$ & $29.9 ; 26.3$ & $75.1 ; 67.5$ & $39.9 ; 42.2$ & $32.4 ; 40.1$ & $36.2 ; 28.3$ & 9026; 9627 & 9223; 9722 & $\begin{array}{c}\text { 3514.8; } \\
34.613 .7\end{array}$ & $62 ; 72.5$ \\
\hline $\begin{array}{l}\text { McNeice (26), } \\
2018\end{array}$ & $\begin{array}{l}\mathrm{CO}-\mathrm{PCl} ; \\
\mathrm{MV}-\mathrm{PCl}\end{array}$ & NA & $75.4 ; 75.3$ & $58.6 ; 59.5$ & $41.6 ; 46.5$ & $29.9 ; 34.6$ & $27.4 ; 19.1$ & NA & NA & $29.3 ; 30.9$ & NA \\
\hline Lee (12), 2019 & $\begin{array}{l}\mathrm{CO}-\mathrm{PCl} ; \\
\mathrm{MV}-\mathrm{PCl}\end{array}$ & $\begin{array}{l}67.312 .8 \\
66.212 .4\end{array}$ & $74.9 ; 73.5$ & $54.6 ; 52.3$ & $46.6 ; 46.9$ & $40.9 ; 41.2$ & $36.3 ; 40.4$ & NA & NA & $\begin{array}{c}4712.7 \\
44.313 .2\end{array}$ & 33.3; 33.8 \\
\hline $\begin{array}{l}\text { Petrovic (27), } \\
2019\end{array}$ & $\begin{array}{l}\text { CO-PCl; } \\
\text { MV-PCl }\end{array}$ & $64.5 ; 70.0$ & $89.3 ; 52.1$ & $50.0 ; 60.6$ & $32.1 ; 19.7$ & $28.6 ; 30.3$ & $21.4 ; 34.5$ & NA & NA & $35.0 ; 35.0$ & NA \\
\hline Lemor (28), 2020 & $\begin{array}{l}\text { o CO-PCl; } \\
\text { MV-PCl }\end{array}$ & $\begin{array}{l}\text { 63.311.6; } \\
64.811 .8\end{array}$ & $76.4 ; 81.8$ & NA & NA & $55.1 ; 55.4$ & NA & 95; 99 & $98 ; 95$ & NA & $50.7 ; 49.2$ \\
\hline Khera (29), 2020 & $\begin{array}{l}\mathrm{CO}-\mathrm{PCl} ; \\
\mathrm{MV}-\mathrm{PCl}\end{array}$ & $66.6 ; 65.9$ & $68.2 ; 68.5$ & $71.4 ; 71.9$ & $58.0 ; 59.8$ & $31.7 ; 35.0$ & $34.5 ; 31.4$ & NA & NA & NA & NA \\
\hline $\begin{array}{l}\text { Rathod (30), } \\
2020\end{array}$ & $\begin{array}{l}\text { CO-PCl; } \\
\text { MV-PCl }\end{array}$ & $\begin{array}{l}68.112 .9 \\
66.513 .2\end{array}$ & $76.6 ; 82.7$ & $48.7 ; 41.6$ & $3.7 ; 34.0$ & $20.7 ; 19.5$ & $37.1 ; 35.2$ & NA & NA & NA & $45.0 ; 43.3$ \\
\hline $\begin{array}{l}\text { Vergara (31), } \\
2021\end{array}$ & $\begin{array}{l}\text { CO-PCl; } \\
\text { MV-PCl }\end{array}$ & $\begin{array}{l}70.512 .7 \\
69.712 .4\end{array}$ & $68.6 ; 66.7$ & $45.3 ; 39.8$ & $27.7 ; 30.1$ & 23.3; 29.0 & $30.8 ; 28.0$ & NA & NA & $\begin{array}{l}29.59 .6 \\
29.68 .2\end{array}$ & $49.7 ; 62.4$ \\
\hline $\begin{array}{l}\text { Thiele }(2,9) \text {, } \\
2018\end{array}$ & $\begin{array}{l}\mathrm{CO}-\mathrm{PCl} ; \\
\mathrm{MV}-\mathrm{PCl}\end{array}$ & $70 ; 70$ & $74.9 ; 78.1$ & $59 ; 61.5$ & $33.1 ; 34.8$ & $30.3 ; 34.6$ & $25.4 ; 27.4$ & $90 ; 91$ & $\begin{array}{l}85-130 \\
83-120\end{array}$ & $33 ; 30$ & $63.6 ; 63.2$ \\
\hline
\end{tabular}

$\mathrm{CO}-\mathrm{PCl}$, culprit-only percutaneous coronary intervention; LVEF, left ventricular ejection fraction; MV-PCl, multivessel percutaneous coronary intervention; NA, not available; SBP, systolic blood pressure. 


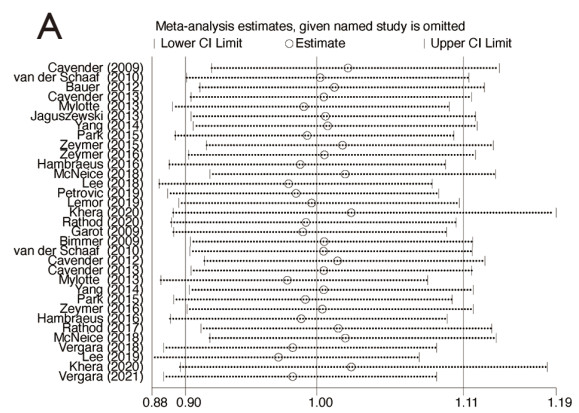

D
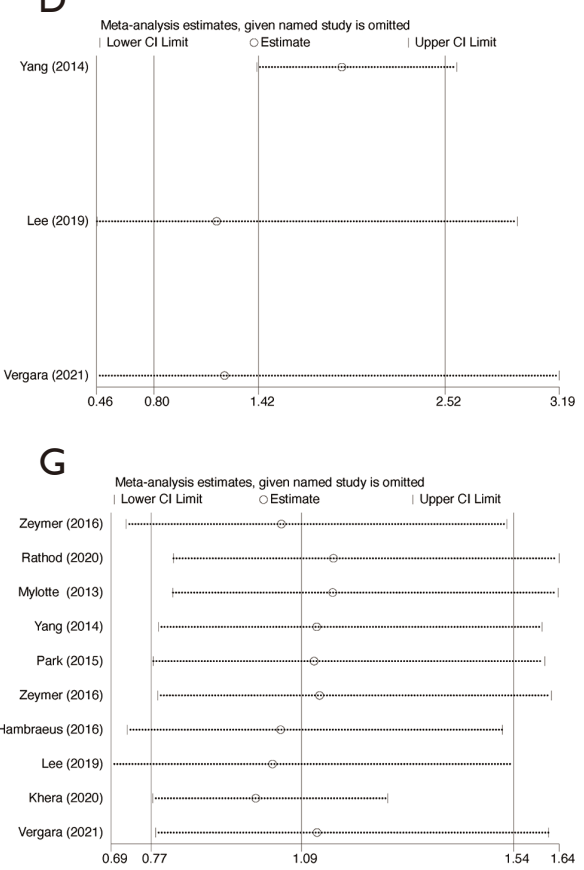

B

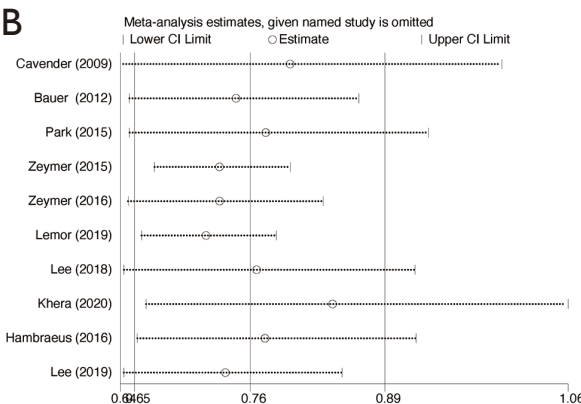

$E$

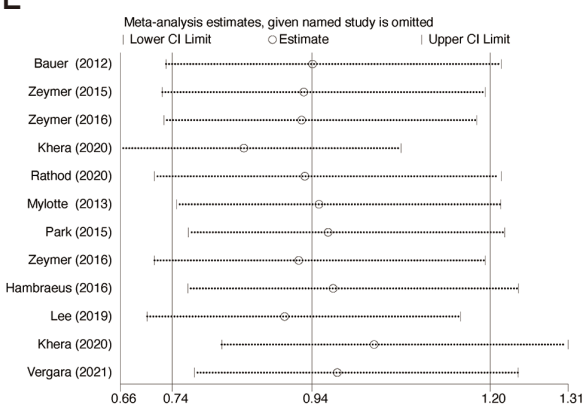

$\mathrm{H}$

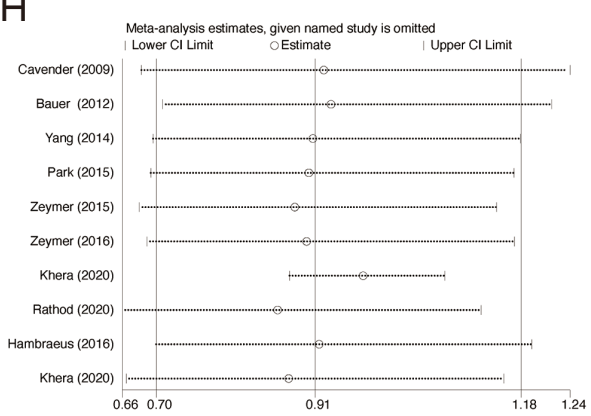

C

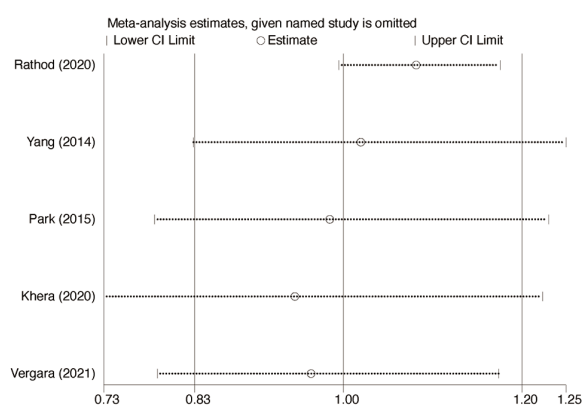

$\mathrm{F}$

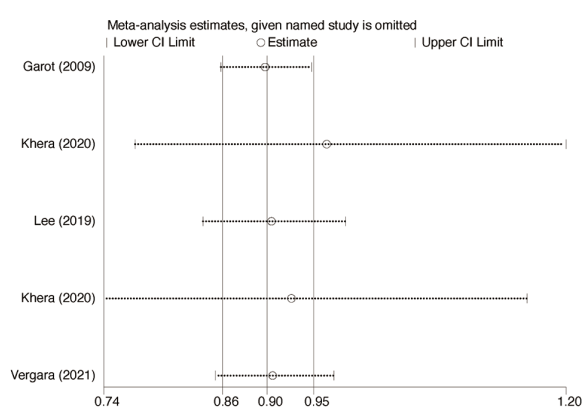

I

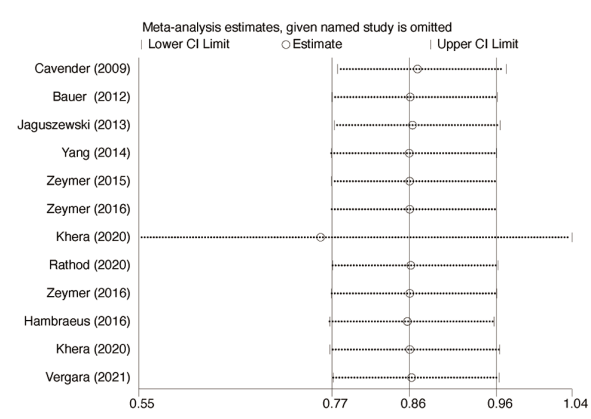

Figure S1 Sensitivity analyses of all-cause mortality (A), renal failure (B), major adverse cardiovascular events (C), cardiac death (D), myocardial infarction (E), heart failure (F), revascularization $(\mathrm{G})$, bleeding $(\mathrm{H})$, and stroke (I). 


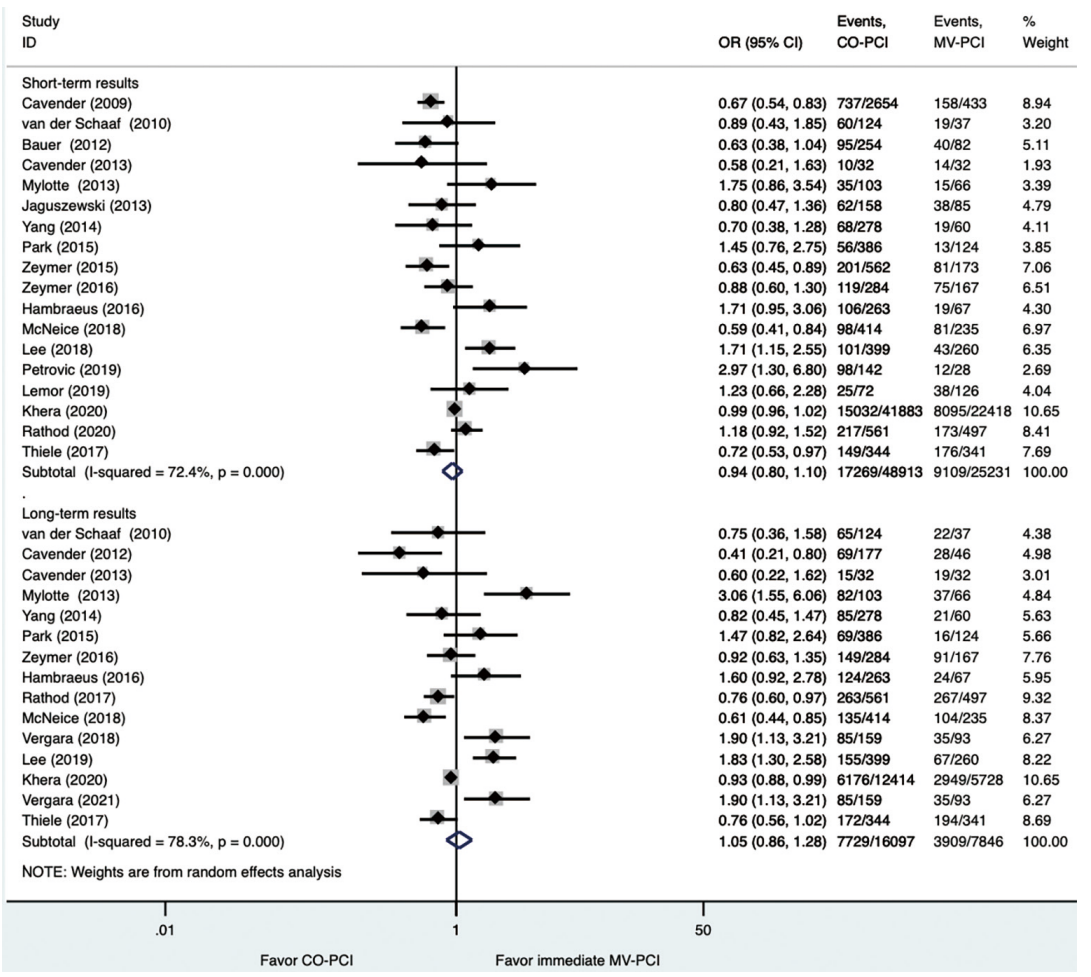

Figure S2 Analysis of all-cause mortality after adding randomized trial.

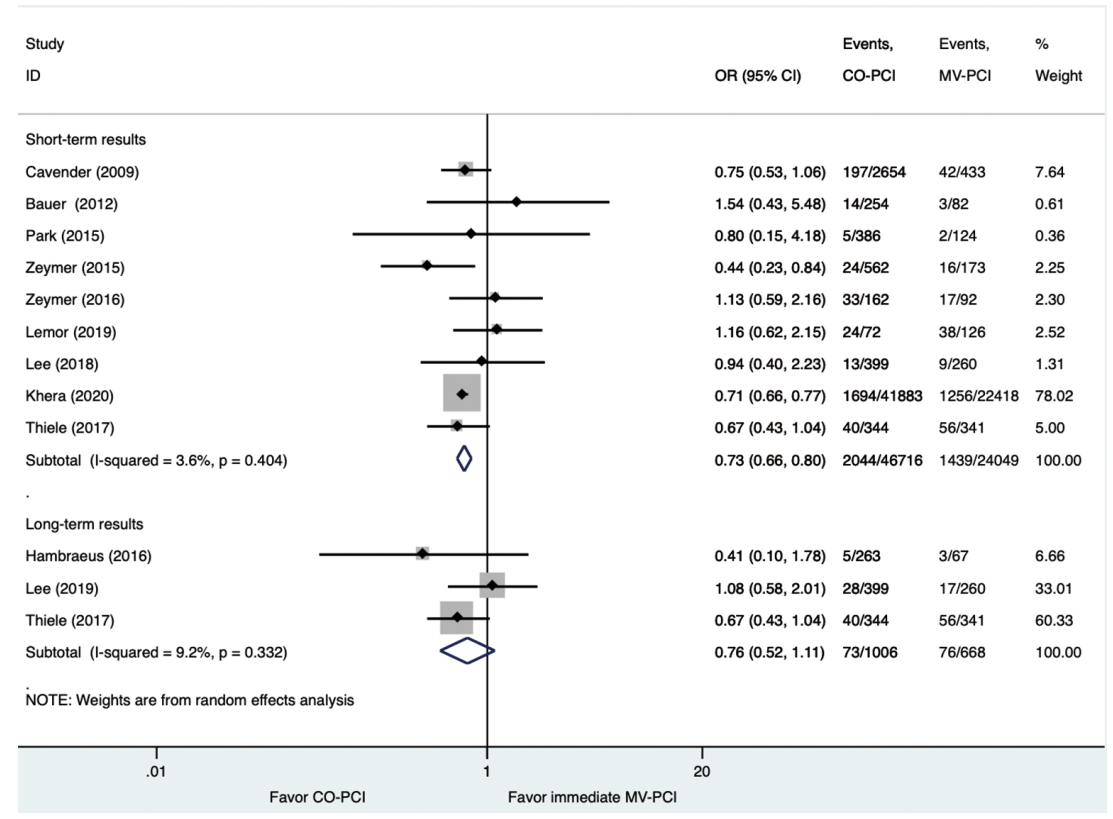

Figure S3 Analysis of renal failure after adding randomized trial. 


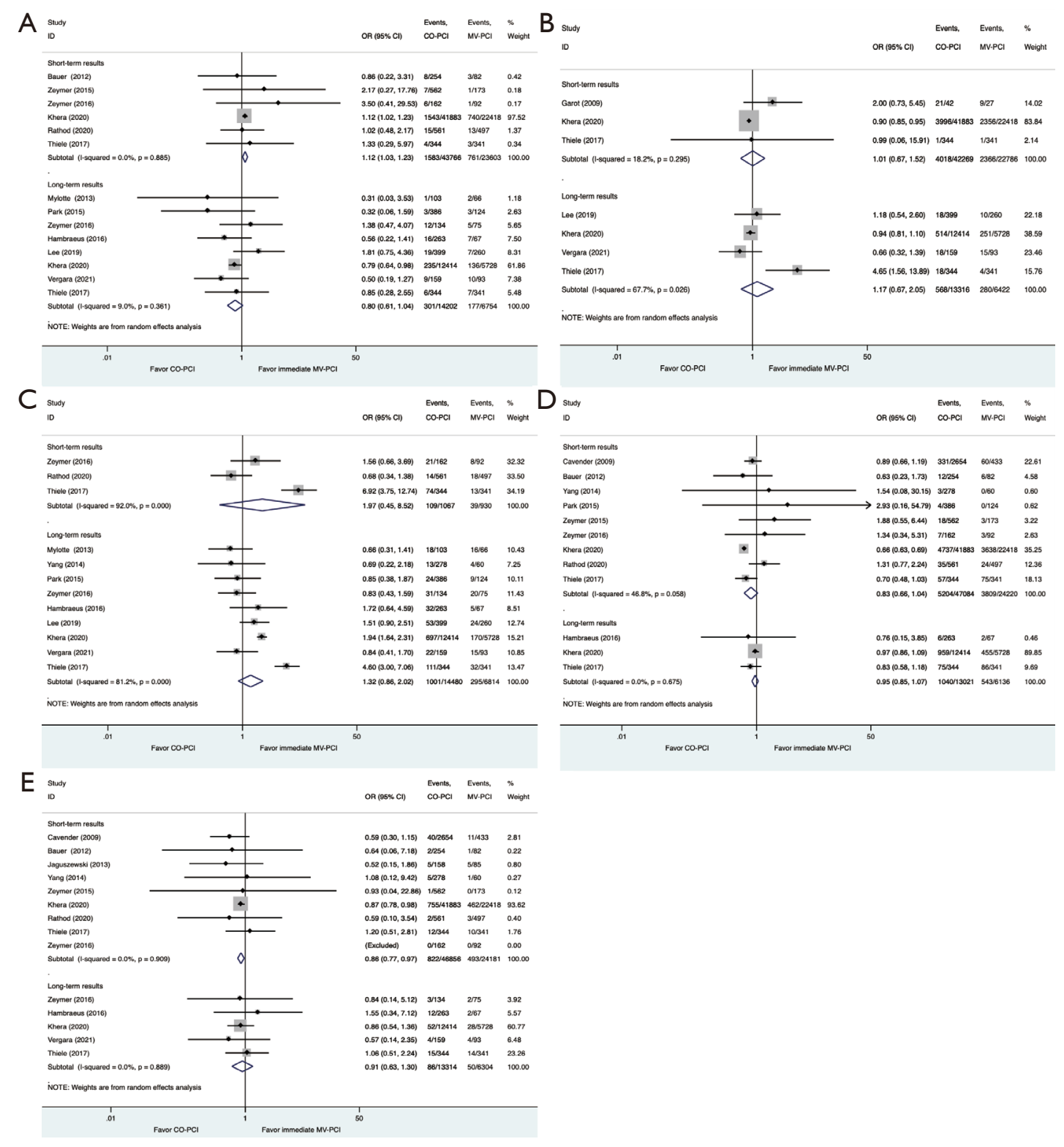

Figure S4 Analysis of myocardial infarction (A), heart failure (B), revascularization (C), bleeding (D), and stroke (E) after adding randomized trial. 

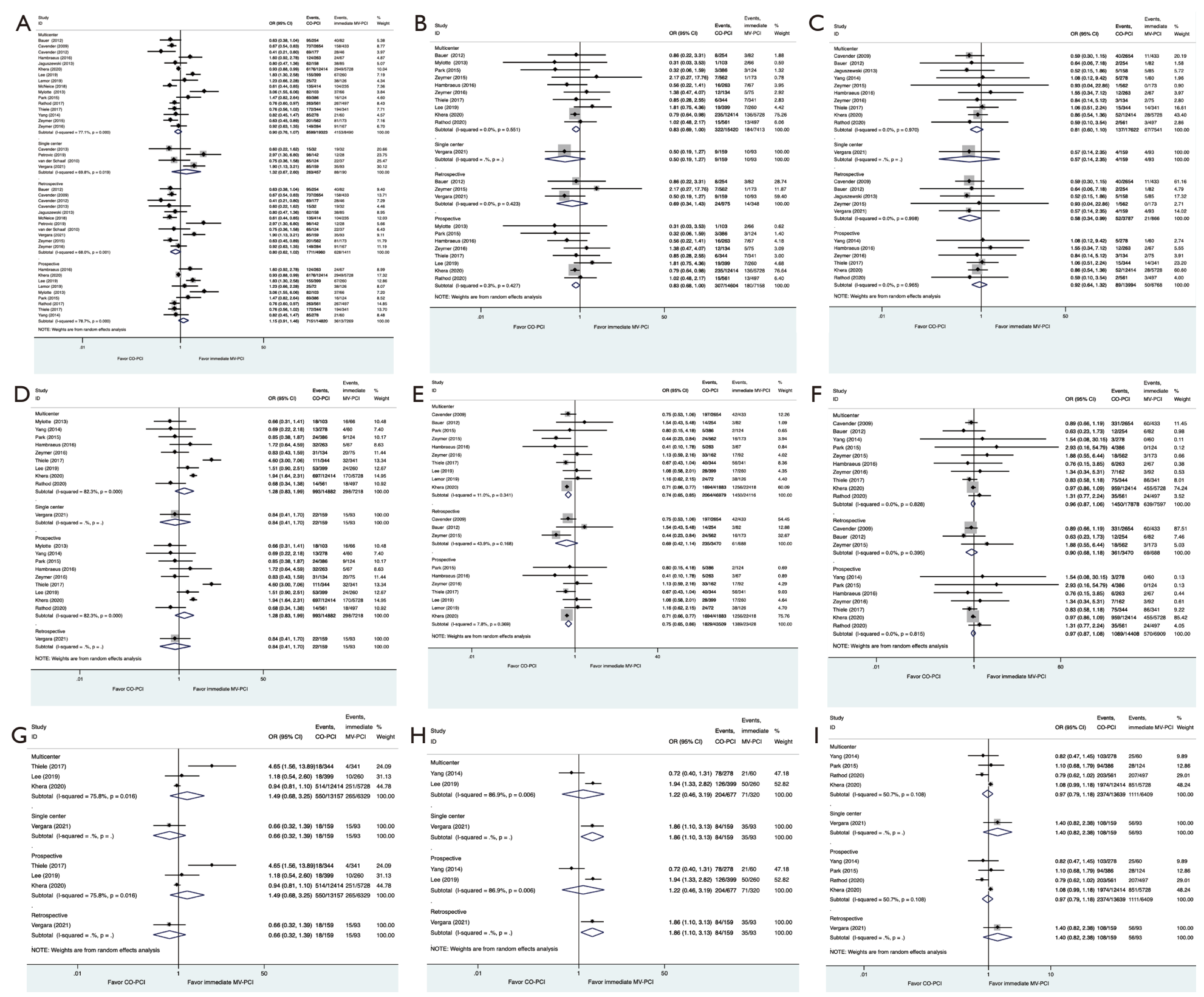

Figure S5 Subgroups analyses of all-cause death (A), myocardial infarction (B), stroke (C), revascularization (D), renal failure (E), bleeding (F), heart failure (G), cardiac death $(\mathrm{H})$, and major adverse cardiovascular events (I) based on prospective versus retrospective, single center versus multicenter studies. 

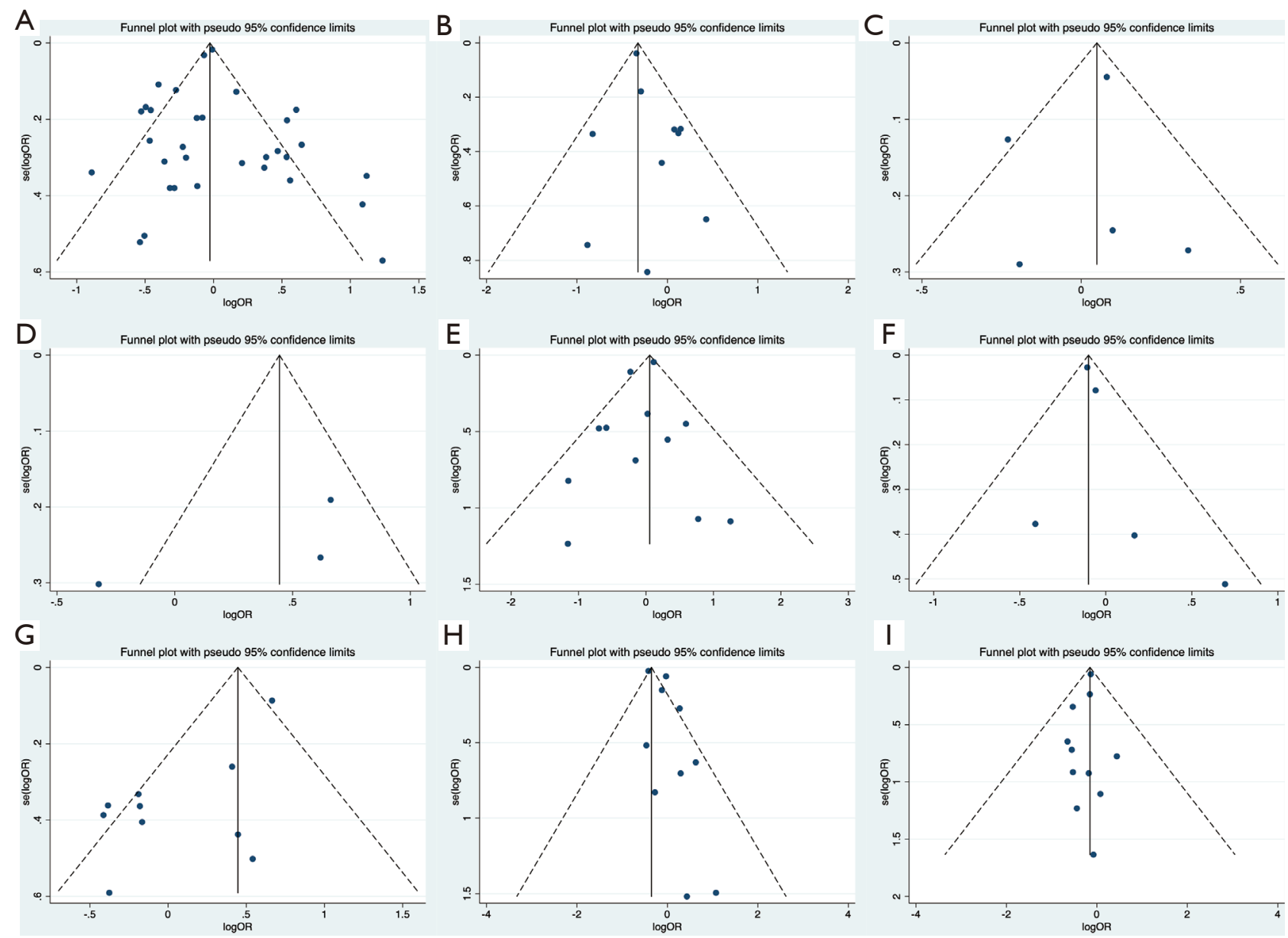

Figure S6 Funnel plot of all-cause mortality (A), renal failure (B), major adverse cardiovascular events (C), cardiac death (D), myocardial infarction (E), heart failure (F), revascularization $(\mathrm{G})$, bleeding $(\mathrm{H})$, and stroke $(\mathrm{I})$. 

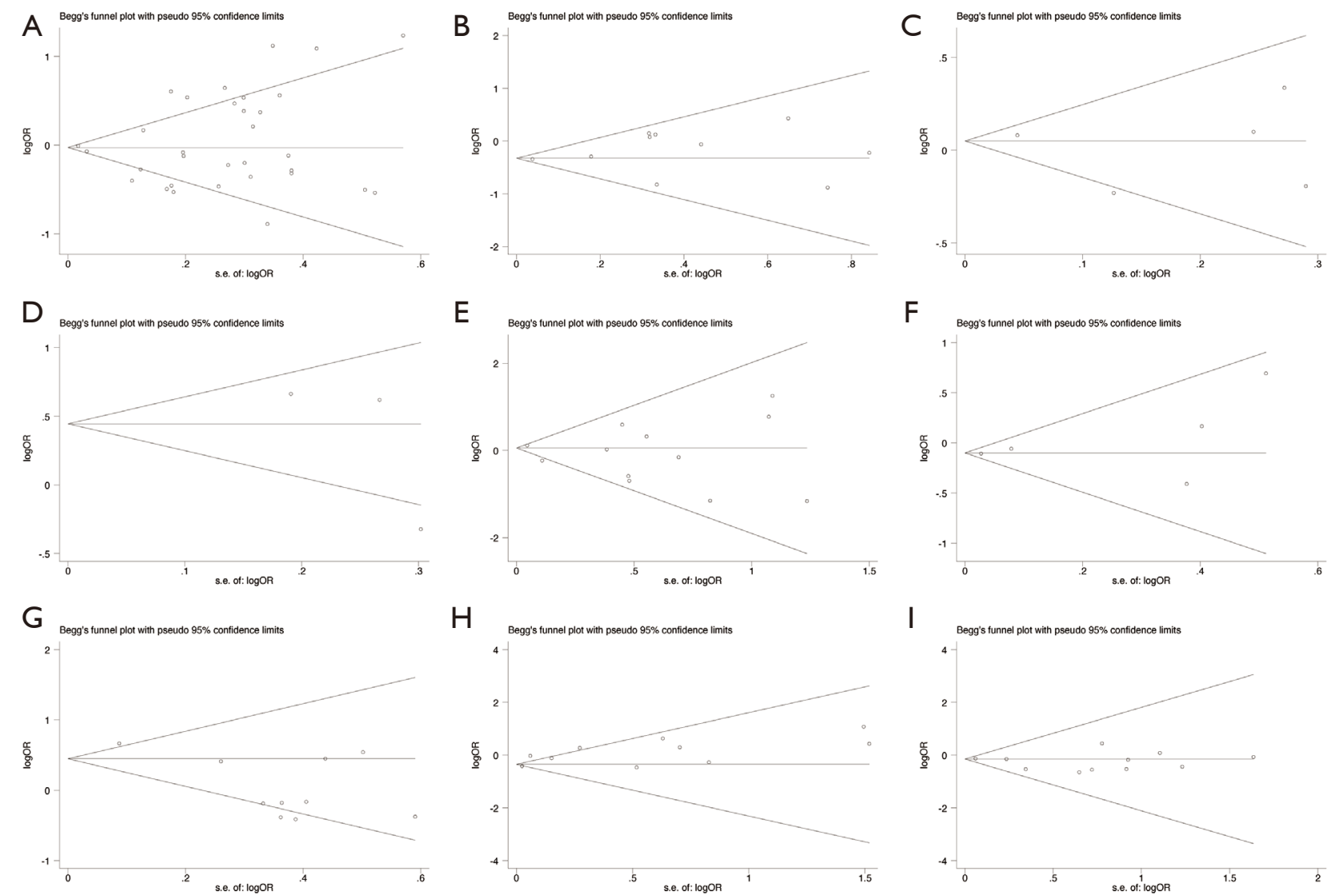

Figure S7 Begg's test of all-cause mortality (A), renal failure (B), major adverse cardiovascular events (C), cardiac death (D), myocardial infarction (E), heart failure (F), revascularization $(\mathrm{G})$, bleeding $(\mathrm{H})$, and stroke $(\mathrm{I})$. 